\section{$\underset{\substack{\text { hommes } \\ \text { \& migrations }}}{ }$}

\section{Hommes \& migrations}

Revue française de référence sur les dynamiques

migratoires

$1309 \mid 2015$

Le $3 e$ âge des migrants

\title{
Déjà 50 ans !
}

\section{Marie Poinsot}

\section{(2) OpenEdition \\ Journals}

\section{Édition électronique}

URL : http://journals.openedition.org/hommesmigrations/3058

DOI : 10.4000/hommesmigrations.3058

ISSN : 2262-3353

\section{Éditeur}

Musée national de l'histoire de l'immigration

\section{Édition imprimée}

Date de publication : 1 janvier 2015

Pagination : 1

ISBN : 978-2-919040-30-8

ISSN : $1142-852 X$

\section{Référence électronique}

Marie Poinsot, « Déjà 50 ans ! », Hommes \& migrations [En ligne], 1309 | 2015, mis en ligne le 16 juillet 2015, consulté le 24 septembre 2020. URL : http://journals.openedition.org/hommesmigrations/3058 ; DOI : https://doi.org/10.4000/hommesmigrations.3058 


\section{DÉJÀ 50 ANS !}

par MARIE POINSOT, rédactrice en chef.

À l'occasion de son jubilée, Hommes \& Migrations s'interroge sur la particularité de son aventure éditoriale. En parcourant les expériences à son actif, la revue questionne sa place dans le paysage intellectuel : savoir d'où elle vient, mesurer les étapes parcourues et réfléchir sur les directions à prendre. Hommes \& Migrations doit beaucoup à sa création par l'association Amana, qui apportait son soutien aux migrants dans l'après-guerre à Paris. L'idée que l'information peut guider les actions de terrain et mieux les qualifier faisait déjà son originalité. Devenue au fil des décennies une revue dite "scientifique" sur les phénomènes migratoires, elle ne s'est pas éloignée de son identité, même si les formats ont évolué. Ses missions perdurent : informer, connaître et reconnaître les migrations, invisibles ou stigmatisées, transformer les regards sur les populations immigrées, nouer un dialogue avec la société entière. Évoquer le chemin parcouru depuis les Cahiers nord-africains nécessiterait de relire les centaines de numéros parus depuis 1965.

C'est en janvier 1987 que Jacques Hauser opère un changement de cap radical : "Le moment semble venu d'affirmer que nous ne voulons pas nous limiter à la compilation de textes divers parus ici et là mais que nous entendons exprimer aussi des points de vue originaux, des analyses inédites ainsi que notre propre interprétation de l'actualité" ( $\mathrm{n}^{\circ}$ 1099). Cette ligne met l'accent sur des articles inédits, sur les témoignages et les reportages. La formule éditoriale sera poursuivie par Philippe Dewitte entre 1989 et 2005, en l'enrichissant. Elle associe des articles de fond sur l'immigration, des commentaires sur l'actualité et des chroniques culturelles. Son rythme mensuel, puis bimestriel et trimestriel depuis 2013 en fait une publication assez réactive qui s'adresse à une audience mixte de chercheurs et d'acteurs de terrain.

Hommes \& Migrations a porté une attention particulière aux nouveaux chantiers de recherche et publié des jeunes chercheurs. L'élargissement du cercle de ses contributeurs lui a permis de dresser une cartographie des lieux où se produisent les recherches avancées sur les migrations. À travers les comparaisons internationales, la revue a tenté de briser les effets ethnocentristes des modèles politico-culturels nationaux en les confrontant aux réalités transnationales par-delà des frontières géographiques ou linguistiques.

Éditée depuis 2007 par la Cité nationale de l'histoire de l'immigration, Hommes \& Migrations a lancé au Palais de la Porte Dorée ou ailleurs une série de rencontres en lien avec des festivals, des salons, des spectacles qui évoquent d'autres dimensions des migrations. La diffusion des savoirs doit emprunter d'autres circuits, au-delà des cercles spécialisés, pour capter d'autres audiences. La revue s'est constituée en ressource pour des débats d'idées sur les enjeux des sociétés face aux migrations. À travers ces échanges, elle aide à reformuler un projet commun autour de thèmes comme l'hospitalité, le rapport à l'altérité, la participation et la citoyenneté, les appartenances, les identités et les cultures, etc.

Pour fêter ses 50 ans, Hommes \& Migrations mise sur son énergie et ses réseaux de collaborateurs. Des chroniques "Spécial 50 ans" comprendront des entretiens, des analyses critiques des contenus éditoriaux, des fac-similés commentés. La revue organisera une série de rencontres professionnelles visant à renforcer les échanges, les réflexions communes, les coproductions, les nouvelles pistes de partenariat avec les domaines scientifiques et culturels intervenant dans son champ thématique. À l'occasion du salon des revues en octobre, Hommes \& Migrations invite d'autres revues à débattre sur leurs missions dans un esprit de liberté et d'audace face aux défis du numérique.

Point d'orgue de l'année, la revue envisage un colloque sur "Les migrations dans 50 ans", qui se tiendra au Musée national de l'histoire de l'immigration, en décembre prochain, en s'articulant autour de thématiques prospectives pour dessiner son cadrage scientifique des années à venir. I 